\title{
Development of Stability Indicating LC Method for the Estimation of Tolperisone in Bulk and Pharmaceutical Dosage Form
}

\author{
U. K. Chhalotiya, ${ }^{1}$ K. K. Bhatt, ${ }^{1}$ D. A. Shah, ${ }^{1}$ S. L. Baldania, ${ }^{1}$ and S. B. Patel ${ }^{2}$ \\ ${ }^{1}$ Department of Pharmaceutical Chemistry and Analysis, Indukaka Ipcowala College of Pharmacy, Beyond GIDC Phase IV, \\ Vithal Udyognagar, New Vallabh Vidyanagar, Anand, Gujarat 388121, India \\ ${ }^{2}$ Department of Pharmacology, Indukaka Ipcowala College of Pharmacy, Beyond GIDC Phase IV, Vithal Udyognagar, \\ New Vallabh Vidyanagar, Anand, Gujarat 388121, India
}

Correspondence should be addressed to U. K. Chhalotiya; usmangani84@gmail.com

Received 13 August 2013; Accepted 28 October 2013

Academic Editor: Rassoul Dinarvand

Copyright (C) 2013 U. K. Chhalotiya et al. This is an open access article distributed under the Creative Commons Attribution License, which permits unrestricted use, distribution, and reproduction in any medium, provided the original work is properly cited.

\begin{abstract}
A rapid, specific, and sensitive reverse phase high performance liquid chromatographic method has been developed and validated for analysis of tolperisone in both bulk and pharmaceutical dosage form. The HPLC method was performed with a reversed phase $\mathrm{C}_{18}$ SunFire column $(250 \mathrm{~mm} \times 4.6 \mathrm{~mm}$ i.d., $5 \mathrm{~mm}$ particle size $)$, detection at $261 \mathrm{~nm}$ and a mixture of methanol, water and $\mathrm{pH}$ 7.5 adjusted by use of $1 \%$ solution of triethylamine $(60: 40)$ as mobile phase. The flow rate was $1.0 \mathrm{~mL} \mathrm{~min}^{-1}$ and effluents were monitored at $261 \mathrm{~nm}$. The retention time of tolperisone was $4.8 \mathrm{~min}$. Tolperisone was subjected to acid and alkali hydrolysis, chemical oxidation, wet hydrolysis, dry heat degradation, and sunlight degradation. The degraded product peaks were well resolved from the pure drug peak with significant difference in their retention time values. Stressed samples were assayed using developed LC method. The proposed method was validated with respect to linearity, accuracy, precision, and robustness. The method was successfully applied to the estimation of tolperisone in tablet dosage forms.
\end{abstract}

\section{Introduction}

Tolperisone (TOL) a central muscle relaxant suitable for cerebral arteriosclerosis and for treating extrapyramidal movement disorders [1] is 2-methyl-1-(4-methylphenyl)-3-(1piperidyl) propan-1-one, a piperidine derivative. Tolperisone has the unique property of mediating muscle relaxation without concomitant sedation and it does not cause coordination, weakness, and mental confusion or withdrawal phenomena, in contrast to other muscle relaxants. Its molecular formula and molecular weight are $\mathrm{C}_{16} \mathrm{H}_{23} \mathrm{NO} \cdot \mathrm{HCl}$ and 281.83, respectively. Tolperisone $\mathrm{HCl}$ is extremely water soluble; it is more stable in acidic medium pH $<4.5$ [2-4]. Comprehensive literature survey reveals that several analytical methods have been reported for the estimation of tolperisone which includes potentiometry [5], spectroscopy [6-8], high performance thin layer chromatography (HPTLC) [9], and high performance liquid chromatography $[10,11]$. The reported
RP-HPLC methods are aimed at quantifying tolperisone in biological fluids $[12,13]$. Literature review revealed that stability indicating RP-HPLC method [14] has been reported for the estimation of tolperisone in pharmaceutical dosage form. In the proposed study, attempt has been made to develop sensitive stability indicating RP-LC method for the estimation of TOL in bulk and pharmaceutical dosage form [15].

\section{Materials and Methods}

\subsection{Instrumentation}

2.1.1. High Performance Liquid Chromatography. The liquid chromatographic system of waters (Calcutta, India) containing HPLC isocratic pump (515), variable wavelength programmable 2998 photodiode array detector, and rheodyne injector with $20 \mu \mathrm{L}$ fixed loop was used. A SunFire $\mathrm{C}_{18}$ 
column with $250 \times 4.6 \mathrm{~mm}$ i.d. and $5 \mu \mathrm{m}$ particle size was used as stationary phase.

2.2. Reagents and Materials. Analytically pure tolperisone (TOL) was procured from Sun Pharmaceutical Pvt. Ltd., (Baroda, India). LC grade of methanol and water was purchased from E. Merck (Mumbai, India). Triethylamine (Sisco research laboratories, Mumbai, India) was of analytical reagent grade. Tablet formulation A (Synaptol-50 (50 mg), Sun Pharmaceutical Pvt. Ltd., Silvassa, Gujarat, India) containing labelled amount of $50 \mathrm{mg}$ of tolperisone was purchased from local market.

2.3. Preparation of Mobile Phase and Stock Solution. Mobile phase was prepared by mixing $950 \mathrm{~mL}$ of methanol with $50 \mathrm{~mL}$ of water. The $\mathrm{pH}$ was adjusted to 7.5 with $1 \%$ triethylamine. The mobile phase was filtered with Whatman filter paper no. $42(0.45 \mu \mathrm{m})$. The mobile phase was sonicated for $15 \mathrm{~min}$ for degassing prior to use.

Stock solution was prepared by accurately weighing $10 \mathrm{mg}$ of TOL and transferring to $10 \mathrm{~mL}$ volumetric flasks containing $3 \mathrm{~mL}$ of methanol. The flask was sonicated for 10 minutes to dissolve the solids. Volume was made up to the mark with methanol, which gave $1000 \mu \mathrm{g} / \mathrm{mL}$. $1 \mathrm{~mL}$ of aliquot from the stock solution was diluted with mobile phase to obtain working standards of $100 \mu \mathrm{g} / \mathrm{mL}$ of drug.

2.4. Chromatographic Conditions. A reversed phase $\mathrm{C}_{18}$ column (SunFire) equilibrated with mobile phase comprising of methanol: water $(95: 05 \mathrm{v} / \mathrm{v} ; \mathrm{pH}$ 7.5) was used. Mobile phase flow rate was maintained at $1 \mathrm{~mL} / \mathrm{min}$ and effluents were monitored at $261 \mathrm{~nm}$. A $20 \mu \mathrm{L}$ of sample was injected using a fixed loop, and the total run time was $10 \mathrm{~min}$. All the chromatographic separations were carried out at controlled room temperature $\left(25 \pm 2^{\circ} \mathrm{C}\right)$.

2.5. Calibration Curves for TOL. Appropriate aliquots of TOL working standard solutions were taken in different $10 \mathrm{~mL}$ volumetric flasks. The volume was made up to the mark with mobile phase to obtain final concentrations of $0.01,0.1,1,10,20$, and $30 \mu \mathrm{g} / \mathrm{mL}$ of TOL, respectively. The solutions were injected using a $20 \mu \mathrm{L}$ fixed loop system and chromatograms were recorded. Calibration curves were constructed by plotting peak area versus concentrations of the drug. The nonweighted linear regression equation was computed for TOL.

2.6. Analysis of Marketed Formulations. Twenty tablets were weighed accurately and finely powdered. Tablet powder equivalent to $50 \mathrm{mg}$ TOL was taken in $25 \mathrm{~mL}$ volumetric flask. A $5 \mathrm{~mL}$ of methanol was added to the above flask and the flask was sonicated for 15 minutes. The solution was filtered into another $25 \mathrm{~mL}$ volumetric flask using Whatman filter paper no. 42 and volume was made up to the mark with the same solvent.

Appropriate aliquot was taken from above solution and transferred to a $10 \mathrm{~mL}$ volumetric flask and the volume was made up to the mark with the mobile phase to obtain a solution containing $10 \mu \mathrm{g} / \mathrm{mL}$ of TOL. The solution was sonicated for $10 \mathrm{~min}$. It was injected as per the above chromatographic conditions and peak area was recorded. The quantifications were carried out by keeping these values to the linear equation of calibration curve.

2.7. Validation of Method. The method was validated as per ICH guideline [16] for accuracy, precision, specificity, detection limit, quantitation limit, and robustness.

2.7.1. Accuracy. Known amount of TOL $(0,5,10,15 \mu \mathrm{g} / \mathrm{mL})$ was added to a prequantified sample solutions. The amount of TOL was estimated using linear regression equation.

2.7.2. Precision. The instrument precision was evaluated by injecting the solution containing TOL $(10 \mu \mathrm{g} / \mathrm{mL})$ three times repeatedly and peak area was measured. The results are reported in terms of \% relative standard deviation. The intraday and interday precision study of TOL was carried out by estimating the corresponding responses 3 times on the same day and on 3 different days (first, second, and third day) for 3 different concentrations of TOL $(0.01,1$, and $30 \mu \mathrm{g} / \mathrm{mL})$ within the calibration range and the results are reported in terms of $\%$ relative standard deviation (RSD).

2.7.3. Specificity [16]. The specificity was estimated by spiking commonly used excipients (starch, talc, and magnesium stearate) into a preweighed quantity of drug. The chromatogram was taken by appropriate dilutions and the quantities of drugs were determined.

2.8. Forced Degradation Study. Stress degradation study using acid and alkali hydrolysis, chemical oxidation, wet hydrolysis exposure to sunlight, and dry heat degradation was carried out and interference of the degradation products was investigated. TOL was weighed $(10 \mathrm{mg})$ and transferred to $10 \mathrm{~mL}$ volumetric flasks and exposed to different stress conditions.

2.8.1. Heat Induced Alkali Hydrolysis. To the $10 \mathrm{~mL}$ volumetric flask, $10 \mathrm{mg}$ of TOL was taken and $2 \mathrm{~mL}$ of $0.1 \mathrm{~N} \mathrm{NaOH}$ was added to perform heat induced base hydrolysis. The flask was heated at $80^{\circ} \mathrm{C}$ for $2 \mathrm{hrs}$ and allowed to cool to room temperature. Solution was neutralized with $0.1 \mathrm{~N} \mathrm{HCl}$ and volume was made up to the mark with methanol. $0.1 \mathrm{~mL}$ of aliquots was taken from the above solution and diluted with mobile phase to obtain final concentration of $10 \mu \mathrm{g} \mathrm{mL} \mathrm{L}^{-1}$ of TOL.

2.8.2. Heat Induced Acid Hydrolysis. To the $10 \mathrm{~mL}$ volumetric flask, $10 \mathrm{mg}$ of TOL was taken and $2 \mathrm{~mL}$ of $0.1 \mathrm{~N} \mathrm{HCl}$ was added to perform heat induced acid hydrolysis. The flask was heated at $80^{\circ} \mathrm{C}$ for $2 \mathrm{hrs}$ and allowed to cool to room temperature. Solution was neutralized with $0.1 \mathrm{~N} \mathrm{NaOH}$ and volume was made up to the mark with methanol. $0.1 \mathrm{~mL}$ of aliquot was taken from the above solution and diluted with mobile phase to obtain final concentration of $10 \mu \mathrm{g} \mathrm{mL}^{-1}$ of TOL.

2.8.3. Heat Induced Wet Hydrolysis. To the $10 \mathrm{~mL}$ volumetric flask, $10 \mathrm{mg}$ of TOL was taken and $2 \mathrm{~mL}$ of HPLC grade 
TABLE 1: Intraday and Interday precision study of the proposed LC method.

\begin{tabular}{|c|c|c|c|c|}
\hline Conc. $(\mu \mathrm{g} / \mathrm{mL})$ & Intraday $\pm \mathrm{SD}^{\mathrm{a}}(n=3)$ & $\%$ RSD & Interday $\pm \mathrm{SD}^{\mathrm{a}}(n=3)$ & $\%$ RSD \\
\hline 0.01 & $8337.333 \pm 102.08$ & 1.22 & $8268.667 \pm 104.1025$ & 1.26 \\
\hline 1 & $781779.7 \pm 7822.402$ & 1.00 & $776999.7 \pm 11086.82$ & 1.43 \\
\hline 30 & $1830034 \pm 13370.88$ & 0.73 & $1832868 \pm 20041.62$ & 1.09 \\
\hline
\end{tabular}

${ }^{\mathrm{a}} \mathrm{SD}$ : standard deviation.

water was added to perform heat induced wet hydrolysis. The flask was heated at $80^{\circ} \mathrm{C}$ for $2 \mathrm{hrs}$ and allowed to cool to room temperature and volume was made up to the mark with methanol. $0.1 \mathrm{~mL}$ of aliquot was taken from the above solution and diluted with mobile phase to obtain final concentration of $10 \mu \mathrm{g} \mathrm{mL}^{-1}$ of TOL.

2.8.4. Heat Induced Oxidative Stress Degradation. To heat induced perform oxidative stress degradation, $10 \mathrm{mg}$ of TOL was taken in $10 \mathrm{~mL}$ volumetric flask and $2 \mathrm{~mL}$ of $3 \%$ hydrogen peroxide was added. The mixture was heated in a water bath at $80^{\circ} \mathrm{C}$ for $2 \mathrm{hrs}$ and allowed to cool to room temperature and volume was made up to the mark with methanol. $0.1 \mathrm{~mL}$ of aliquot was taken from the above solution and diluted with mobile phase to obtain final concentration of $10 \mu \mathrm{g} \mathrm{mL}^{-1}$ of TOL.

2.8.5. Dry Heat Degradation. Analytically pure $10 \mathrm{mg}$ sample of TOL was exposed in oven at $80^{\circ} \mathrm{C}$ for $2 \mathrm{hrs}$. The solid was allowed to cool and was transferred to volumetric flasks $(10 \mathrm{~mL})$ and dissolved in few $\mathrm{mL}$ of methanol. Volume was made up to the mark with the methanol. Solution was further diluted with mobile phase to obtain final concentration of $10 \mu \mathrm{g} \mathrm{mL}^{-1}$ of TOL.

2.8.6. Photolytic Degradation. Analytically pure $10 \mathrm{mg}$ of drug was exposed to sunlight for $24 \mathrm{hrs}$. The solid was allowed to cool and was transferred to volumetric flask $(10 \mathrm{~mL})$ and dissolved in few $\mathrm{mL}$ of methanol. Volume was made up to the mark with the methanol. Solution was further diluted with the mobile phase to obtain final concentration of $10 \mu \mathrm{g} \mathrm{mL}^{-1}$ of TOL.

All the solutions were injected in the liquid chromatographic system and chromatograms were recorded.

2.8.7. Limit of Detection and Quantification. The detection limit is defined as the lowest concentration of an analyte that can reliably be differentiated from background levels. Limit of quantification of an individual analytical procedure is the lowest amount of analyte that can be quantitatively determined with precision and accuracy. LOD and LOQ were calculated using the following equation as per ICH guidelines. $\mathrm{LOD}=3.3 \times \sigma / S$ and $\mathrm{LOQ}=10 \times \sigma / S$, where $\sigma$ is the standard deviation of $y$-intercepts of regression lines and $S$ is the slope of the calibration curve.

2.8.8. Robustness. Robustness of the method was studied by deliberately changing the experimental conditions like flow rate and percentage of organic phase and also by observing the stability of the sample solution at $25 \pm 2^{\circ}$ for $24 \mathrm{~h}$. The sample solution was assayed at every $2 \mathrm{~h}$ interval up to $24 \mathrm{~h}$.

\section{Result}

\subsection{Validation of the Proposed Methods}

3.1.1. Linearity. The calibration curve $(n=5)$ for TOL was found to be linear in the range of $0.01-30 \mu \mathrm{g} \mathrm{mL}^{-1}$ with a correlation coefficient of 0.9990 . The standard deviation value of slope and intercept of TOL was found to be 605.36 and 8210.51, respectively, which indicated strong correlation between peak area and concentration. The average $(n=5)$ regression equation of calibration curves was obtained as $y=$ $61442 x+11138$.

3.1.2. Precision. Instrument precision was determined by performing injection repeatability test and the $\%$ RSD value for TOL was found to be 1.02. The intraday and interday precision studies were carried out and the \% RSD value was found to be $0.73-1.22$ and 1.09-1.43, respectively (Table 1). The low RSD values indicate that the method is precise.

3.1.3. Accuracy. The accuracy of the method was determined by calculating recoveries of TOL by method of standard addition. The recoveries were found to be $97.85-101.21 \%$ for TOL (Table 2). The high values indicate that the method is accurate.

3.1.4. Limit of Detection and Limit of Quantification. The detection limit and quantitation limit for TOL was $0.005 \mu \mathrm{g} \mathrm{mL}^{-1}$ and $0.01 \mu \mathrm{g} \mathrm{mL}^{-1}$, respectively. The above data shows that a nanogram quantity of the drug can be accurately and precisely determined.

3.1.5. Specificity. The specificity study was carried out to check the interference from the excipients used in the formulation by preparing synthetic mixture containing the drug and excipients. The chromatogram showed peaks for the drug without any interfering peak.

3.1.6. Robustness. The method was found to be robust, as small but deliberate changes in the method parameters have no detrimental effect on the method performance as shown in Table 4. The low value of relative standard deviation was indicating that the method was robust.

3.2. Forced Degradation Study. Chromatogram of base hydrolysis performed at $80^{\circ} \mathrm{C}$ for $2 \mathrm{hrs}$ reflux showed degradation of TOL with degradation product peak at retention times (RT) 3.261, $3.91 \mathrm{~min}$, and $4.02 \mathrm{~min}$ (Figure 3). Chromatogram of acid hydrolysis performed at $80^{\circ} \mathrm{C}$ for $24 \mathrm{hrs}$ 
TABLE 2: Accuracy study of the proposed LC method.

\begin{tabular}{|c|c|c|c|c|c|c|c|}
\hline $\begin{array}{l}\text { Amount of sample } \\
(\mu \mathrm{g} / \mathrm{mL})\end{array}$ & Sets & $\begin{array}{c}\text { Amount drug of } \\
\text { spiked } \\
(\mu \mathrm{g} / \mathrm{mL})\end{array}$ & Area $(n=3)$ & $\begin{array}{c}\text { Average amount } \\
\text { recovered } \\
(\mu \mathrm{g} / \mathrm{mL})\end{array}$ & $\%$ recovery & $\begin{array}{l}\text { Mean } \\
\text { \% recovery }\end{array}$ & $\%$ RSD \\
\hline \multirow{3}{*}{10} & 1 & 0 & 610609 & \multirow{3}{*}{9.79} & 97.57 & & \multirow{3}{*}{1.22} \\
\hline & 2 & 0 & 605849 & & 96.79 & 97.85 & \\
\hline & 3 & 0 & 620523 & & 99.18 & & \\
\hline \multirow{3}{*}{10} & 1 & 5 & 924702 & \multirow{3}{*}{15.01} & 98.69 & & \multirow{3}{*}{1.01} \\
\hline & 2 & 5 & 932138 & & 99.89 & 100.11 & \\
\hline & 3 & 5 & 943422 & & 101.73 & & \\
\hline \multirow{3}{*}{10} & 1 & 10 & 1238944 & \multirow{3}{*}{19.96} & 99.83 & & \multirow{3}{*}{0.51} \\
\hline & 2 & 10 & 1243225 & & 100.53 & 99.63 & \\
\hline & 3 & 10 & 1230848 & & 98.51 & & \\
\hline \multirow{3}{*}{10} & 1 & 15 & 1534587 & \multirow{3}{*}{25.12} & 97.95 & & \multirow{3}{*}{1.15} \\
\hline & 2 & 15 & 1560664 & & 102.19 & 101.21 & \\
\hline & 3 & 15 & 1568607 & & 103.49 & & \\
\hline
\end{tabular}

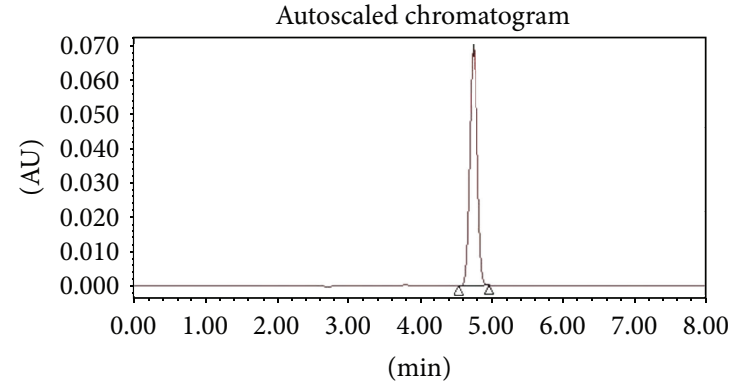

(a)

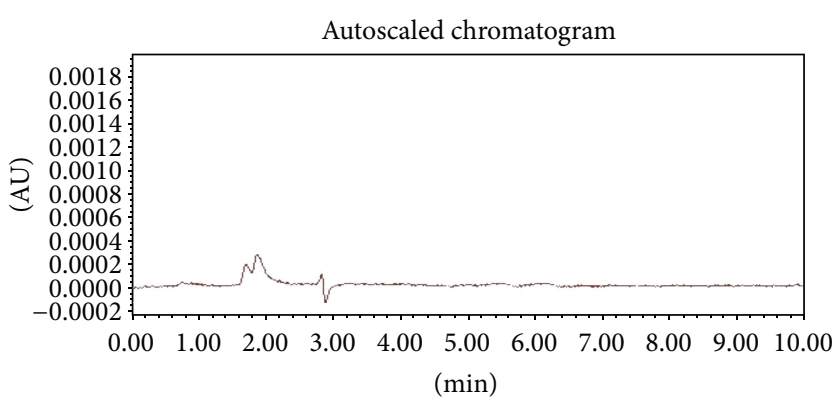

(b)

FIGURE 1: (a) Chromatogram of TOL (RT 4.8) on $\mathrm{C}_{18}$ SunFire column using methanol : water (95:05, v/v, pH 7.5 adjusted with $1 \%$ solution of triethylamine) as the mobile phase. (b) Chromatogram of placebo.

TABLE 3: Data derived from forced degradation study of TOL for the proposed LC method.

\begin{tabular}{lccc}
\hline Condition & Time & $\begin{array}{c}\text { \% recovery } \\
\text { TOL }\end{array}$ & $\begin{array}{c}\text { Retention time of } \\
\text { degradation products } \\
\text { (minutes) }\end{array}$ \\
\hline $0.1 \mathrm{~N} \mathrm{NaOH}^{\mathrm{a}}$ & $2 \mathrm{hrs}$ & 66.69 & $3.26,3.91,4.02$ \\
$0.1 \mathrm{~N} \mathrm{HCl}^{\mathrm{a}}$ & $24 \mathrm{hrs}$ & 85.70 & 4.03 \\
$3 \% \mathrm{H}_{2} \mathrm{O}_{2}{ }^{\mathrm{a}}$ & $2 \mathrm{hrs}$ & 86.30 & 4.02 \\
Dry heat $^{\mathrm{a}}$ & $2 \mathrm{hrs}$ & 83.50 & 6.78 \\
Sunlight & $24 \mathrm{hrs}$ & 82.58 & $4.10,4.63,5.96$ \\
\hline
\end{tabular}

${ }^{\text {a }}$ Samples were heated at $80^{\circ} \mathrm{C}$ for specified period of time.

reflux showed degradation of TOL with degradation product peak at retention time (RT) 4.03 min (Figure 4).

The chromatogram of oxidized TOL with $3 \%$ hydrogen peroxide at $80^{\circ} \mathrm{C}$ for $2 \mathrm{hrs}$ reflux showed degradation of TOL with degradation product peak at retention time (RT) $4.02 \mathrm{~min}$ (Figure 5). The chromatogram of TOL exposed to dry heat at $80^{\circ} \mathrm{C}$ for $2 \mathrm{hrs}$ showed degradation of TOL with degradation product peak at retention time (RT) $6.76 \mathrm{~min}$ (Figure 6). The chromatogram of TOL exposed to sunlight for

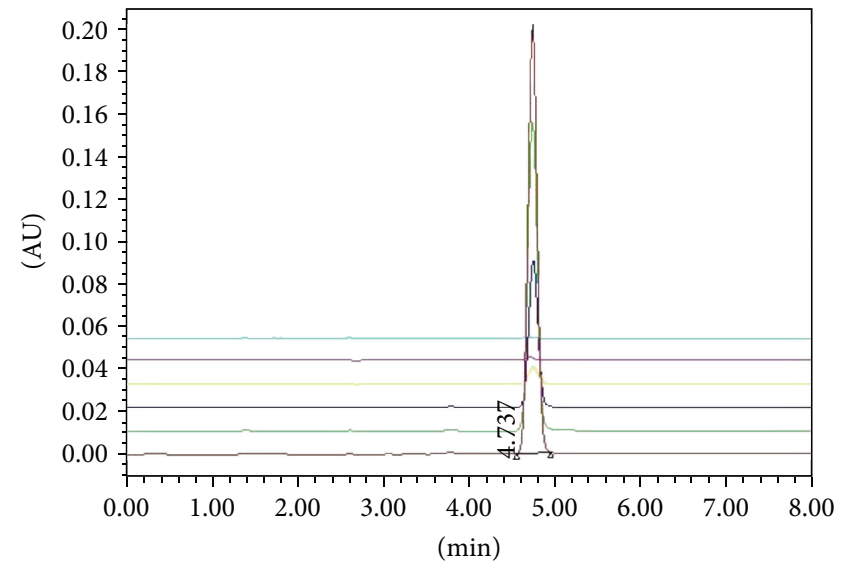

FIgURE 2: Overlay chromatogram of TOL (RT 4.737) on $\mathrm{C}_{18}$ SunFire column using methanol: water (95:05, v/v, pH 7.5 adjusted with $1 \%$ solution of triethylamine) as the mobile phase.

24 hrs showed degradation of TOL with degradation product peak at retention times (RT) 3.63, $4.10 \mathrm{~min}$, and $5.96 \mathrm{~min}$ (Figure 7). 
TABLE 4: Data derived from robustness of TOL for the proposed LC Method.

\begin{tabular}{|c|c|c|c|c|c|}
\hline Parameters & Normal condition & Change in condition & Area $(n=3)$ & $\%$ recovery & Change in \% RSD \\
\hline \multirow{2}{*}{ Flow rate } & \multirow{2}{*}{$1.0 \mathrm{~mL} / \mathrm{min}$} & $0.9 \mathrm{~mL} / \mathrm{min}$ & 75773.67 & 100.36 & 1.21 \\
\hline & & $1.1 \mathrm{~mL} / \mathrm{min}$ & 73762.33 & 101.92 & 1.02 \\
\hline \multirow{2}{*}{ Mobile phase ratio } & \multirow{2}{*}{ Methanol: water $(95: 05)$} & $(97: 03)$ & 71898.33 & 98.83 & 1.15 \\
\hline & & $(93: 07)$ & 71966.33 & 99.00 & 0.92 \\
\hline \multirow{2}{*}{$\mathrm{pH}$ of mobile phase } & \multirow{2}{*}{$\mathrm{pH} 7.5$} & 7.0 & 73415.33 & 101.36 & 1.08 \\
\hline & & 8.0 & 72573 & 99.99 & 0.97 \\
\hline
\end{tabular}

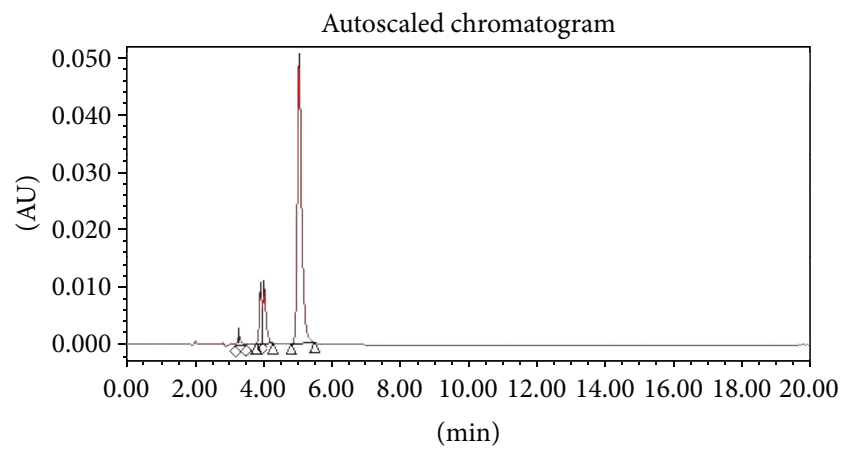

Figure 3: Chromatogram of $0.1 \mathrm{M} \mathrm{NaOH}$ treated TOL at $80^{\circ} \mathrm{C}$ temperature for $2 \mathrm{hrs}$ reflux.

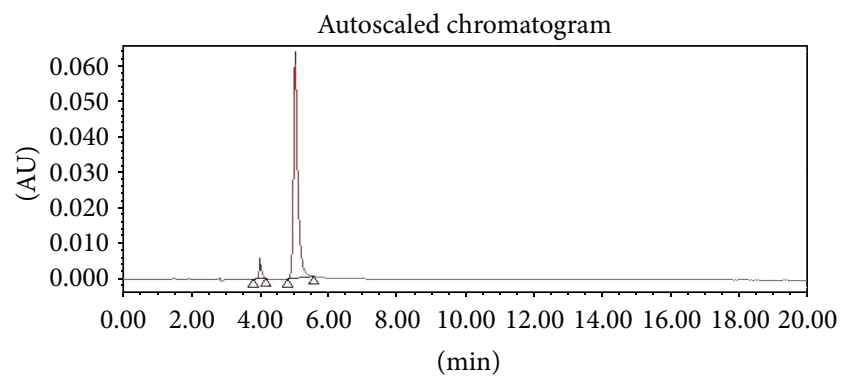

Figure 4: Chromatogram of $0.1 \mathrm{M} \mathrm{HCl}$ (acid hydrolysis) treated TOL at $80^{\circ} \mathrm{C}$ temperature for $24 \mathrm{hrs}$ reflux.

The degradation study thereby indicated that TOL was found to be susceptible to base hydrolysis, acid hydrolysis, oxidation ( $3 \%$ hydrogen peroxide), photo degradation, and dry heat (Table 3 ). No degradation products from different stress conditions affected the determination of TOL.

3.3. Solution Stability. The solution stability study showed that TOL was evaluated at room temperature for $24 \mathrm{hr}$. The relative standard deviation was found below $2.0 \%$. It showed that solution was stable up to $24 \mathrm{hrs}$ at room temperature.

3.4. Analysis of Marketed Formulations. The proposed method was successfully applied to the determination of TOL in their tablet dosage form (Tablet A). The \% recovery for TOL for Tablet "A" was found to be $99.21 \pm 1.28$ mean value standard deviation of three determinations which was comparable with the corresponding labelled amounts.

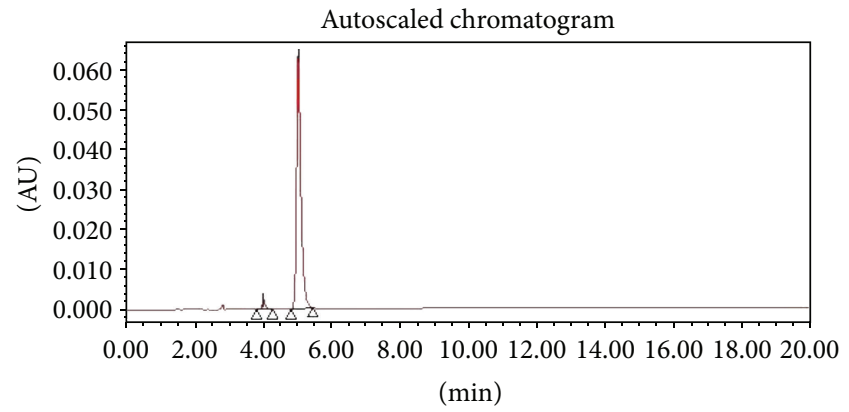

Figure 5: Chromatogram of $3 \% \mathrm{H}_{2} \mathrm{O}_{2}$ treated TOL at $80^{\circ} \mathrm{C}$ temperature for $2 \mathrm{hrs}$ reflux.

\section{Discussion}

4.1. Optimization of Mobile Phase. The objective of the method development was to resolve chromatographic peaks for active drug ingredients and degradation products produced under stressed conditions with less asymmetric factor.

Various mixtures containing water, methanol, and acetonitrile were tried as mobile phases in the initial stage of method development. Mixture of methanol: water $(90: 10, \mathrm{v} / \mathrm{v})$, methanol-water $(60: 40, \mathrm{v} / \mathrm{v})$, and acetonitrilewater $(50: 50, \mathrm{v} / \mathrm{v})$ were tried as mobile phase but satisfactory resolution of drug and degradation peaks were not achieved.

The mobile phase methanol: water $(95: 05, \mathrm{v} / \mathrm{v} \mathrm{pH}$ adjusted with $1 \%$ solution of TEA) was found to be satisfactory and gave symmetric peak for TOL. The retention time for the proposed method was found to be $4.8 \mathrm{~min}$ as shown in Figure 1(a). The chromatogram of placebo is shown in Figure 1(b) and the overlay chromatograms of calibration rage were shown in Figure 2. The system suitability parameters, theoretical plates per meter and asymmetric factor for TOL, were found to be 3805 and 0.87 , respectively. The mobile phase flow rate was maintained at $1.0 \mathrm{~mL} \mathrm{~min}^{-1}$. The UV spectra of the drug showed that TOL was absorbed appreciably at $261 \mathrm{~nm}$, so detection was carried out at $261 \mathrm{~nm}$.

4.2. Method Validation. The calibration curve was found to be linear over the range of $0.01-30 \mu \mathrm{g} / \mathrm{mL}$ for TOL. Instrument precision was determined by performing injection repeatability test and the \% RSD value for TOL was found to be $0.74-1.24 \%$. The intraday and interday precision studies were carried out. For the intraday study \% RSD values were found to be $0.73-1.22 \%$ for TOL and for interday precision 


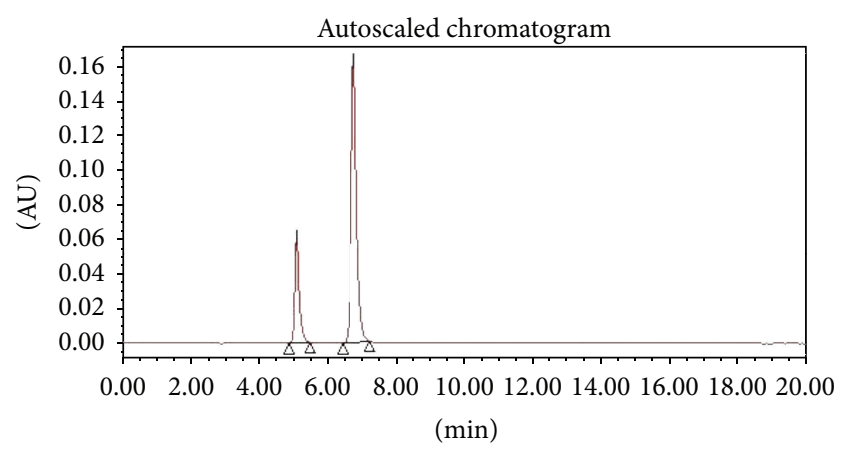

Figure 6: Chromatogram of dry heat TOL at $80^{\circ} \mathrm{C}$ temperature for $2 \mathrm{hrs}$ reflux.

study \% RSD values were found to be $1.09-1.43 \%$ for TOL. The low \% RSD values indicate that the method is precise.

The accuracy of the method was determined by calculating recoveries of TOL by method of standard additions. The recovery obtained was $98.61-101.21 \%$ for TOL. The values indicate that the method is accurate.

The detection limits for TOL were $0.005 \mu \mathrm{g} / \mathrm{mL}$ while quantitation limits were $0.01 \mu \mathrm{g} / \mathrm{mL}$. The above data shows that a nanogram quantity of the drug can be accurately and precisely determined. System suitability test was carried out on freshly prepared standard stock solution of TOL.

The liquid chromatogram of the placebo used in the specificity study did not give any interfering peak in the chromatogram, which suggests that the proposed LC method is both selective and specific.

The method was found to be robust, as small but deliberate changes in the method parameters have no detrimental effect on the method performance. The low value of percentage relative standard deviation was indicating that the method was robust.

The solution stability study revealed that TOL solution was stable for $24 \mathrm{~h}$ without detection of degradation. The percentage recoveries of both the drugs were found to be satisfactory.

4.3. Forced Degradation Study. The degradation study thereby indicated that TOL was found to be susceptible to base hydrolysis, acid hydrolysis, oxidation (3\% hydrogen peroxide), dry heat and photo degradation. No degradation products from different stress conditions affected the determination of TOL.

\section{Conclusion}

As compared with the published, the proposed method is more sensitive. The published method [15] shows the degradation of tolperisone in oxidative stress condition while the proposed method shows the degradation of tolperisone in alkali hydrolysis, wet hydrolysis, oxidative, dry heat degradation, and photo degradation. There was no degradation reported in acid and base hydrolysis in published paper which might be because of less severe conditions $(0.01 \mathrm{~N} \mathrm{HCl}, 0.01 \mathrm{~N} \mathrm{NaOH})$ used to perform stress testing.

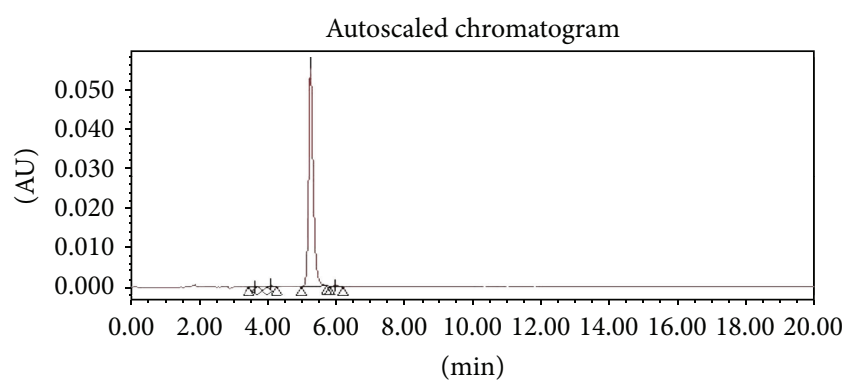

FIGURE 7: Chromatogram of sunlight treated TOL for $24 \mathrm{hrs}$.

The proposed study describes stability indicating LC method for the estimation of TOL in bulk and their pharmaceutical dosage form. The method was validated and found to be simple, sensitive, accurate, and precise. Statistical analysis proved that method to be repeatable and selective for the analysis of TOL without any interference from the excipients. The method was successfully used for the determination of drug in their pharmaceutical formulation. Also the above results indicated the suitability of the method for acid, base, oxidation, dry heat, and photolytic degradation study. As the method separates the drugs from its degradation products, it can be used for analysis of stability samples. The method is suitable for the routine analysis of TOL in tablets. In addition, the HPLC procedure can be applied to the analysis of samples obtained during accelerated stability experiments to predict expiration dates of pharmaceuticals.

\section{Acknowledgments}

The authors are thankful to Sun Pharmaceuticals Ltd., Baroda, for providing gratis sample of asenapine. The authors are very thankful to SICART and Indukaka Ipcowala College of Pharmacy, New Vallabh Vidyanagar, Anand, for providing the necessary facilities to carry out research work.

\section{References}

[1] M. V. Gandhi and B. S. Thompson, Smart Materials and Structures, Chapman \& Hall, London, UK, 1992.

[2] G. Orgován, K. Tihanyi, and B. Noszál, "NMR analysis, protonation equilibria and decomposition kinetics of tolperisone," Journal of Pharmaceutical and Biomedical Analysis, vol. 50, no. 5, pp. 718-723, 2009.

[3] N. Sae-Lee and N. Sae-Lee, "Effects of temperature and humidity on stability of tolperisone hydrochloride," Journal of Pharmaceutical Sciences, vol. 10, pp. 121-124, 2005.

[4] N. Sae-Lee and N. Sae-Lee, "The effect of temperature on stability of tolperisone hydrochloride solution," Thai Pharmaceutical and Health Science Journal, vol. 11, pp. 1-4, 2006.

[5] The Pharmacopoeia of Japan, vol. 2, Ministry of Health, Labour and Welfare, Prefectural office in Japan, 11th edition, 1986.

[6] The Pharmacopoeia of Japan, vol. 2, Ministry of Health, Labour and Walfare, Prefectural office in Japan, 12th edition, 1991.

[7] V. Jagathi, M. Shaiba, K. Raghavi, M. Sindhura, and R. Prashanthi, "Assay of tolperisone by extractive spectrophotometry," 
Research Journal of Pharmaceutical, Biological and Chemical Sciences, vol. 1, no. 3, pp. 654-657, 2010.

[8] P. Sai Praveen, B. Anupama, V. Jagathi, and G. Devala Rao, "Spectrophotometric determination of Tolperisone using 2, 4-dinitrophenylhydrazine reagent," International Journal of Research in Pharmaceutical Sciences, vol. 1, no. 3, pp. 317-320, 2010.

[9] S. Liawruangrath and B. Liawruangrath, "High performance thin layer chromatographic determination of tolperisone hydrochloride," Journal of Pharmaceutical and Biomedical Analysis, vol. 20, no. 1-2, pp. 401-404, 1999.

[10] S. Liawruangrath, B. Liawruangrath, and P. Pibool, "Simultaneous determination of tolperisone and lidocaine by high performance liquid chromatography," Journal of Pharmaceutical and Biomedical Analysis, vol. 26, no. 5-6, pp. 865-872, 2001.

[11] M. Murali and P. V. Satyanarayana, "Simple validated isocratic RP-HPLC method for estimation of tolperisone in bulk and pharmaceutical dosage form," Der Pharma Chemica, vol. 3, no. 5, pp. 13-19, 2011.

[12] J.-W. Bae, Y.-S. Park, U.-D. Sohn et al., "HPLC determination of tolperisone in human plasma," Archives of Pharmacal Research, vol. 29, no. 4, pp. 339-342, 2006.

[13] T. Yokoyama, K. Fukuda, S. Mori, M. Ogawa, and K. Nagasawa, "Determination of tolperisone enantiomers in plasma and their disposition in rats," Chemical and Pharmaceutical Bulletin, vol. 40, no. 1, pp. 272-274, 1992.

[14] I. Carolin Nimila, P. Balan, N. Chiranjeevi, V. Uma Maheswari, and M. Karthikeyan, "Method development, validation and forced degradation studies of tolperisone hydrochloride by RPHPLC method in bulk and tablet dosage form," International Journal of Pharma and Bio Sciences, vol. 2, no. 4, pp. 587-595, 2011.

[15] International Conference on Harmonization (ICH), Validation of Analytical Procedures: Methodology (Q2R1), Food and Drug Administration, Silver Spring, Md, USA, 2005.

[16] S. Ahuja and S. Scypinski, Handbook of Modern Pharmaceutical Analysis, vol. 3, Academic Press, London, UK, 2001. 

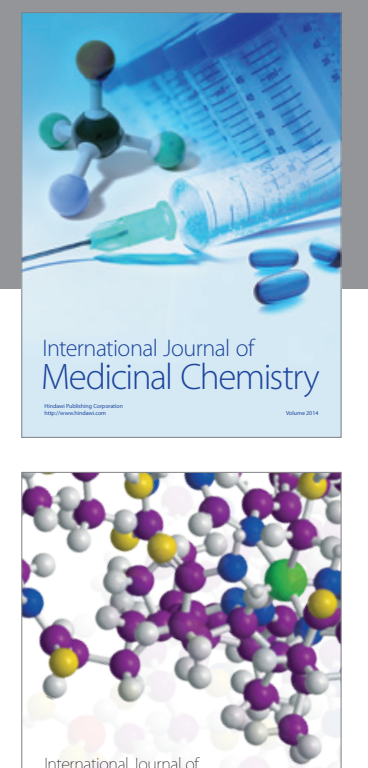

\section{Carbohydrate} Chemistry

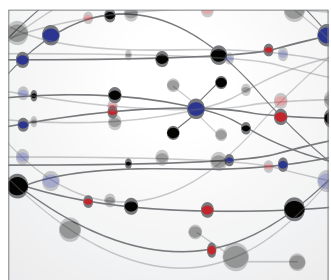

The Scientific World Journal
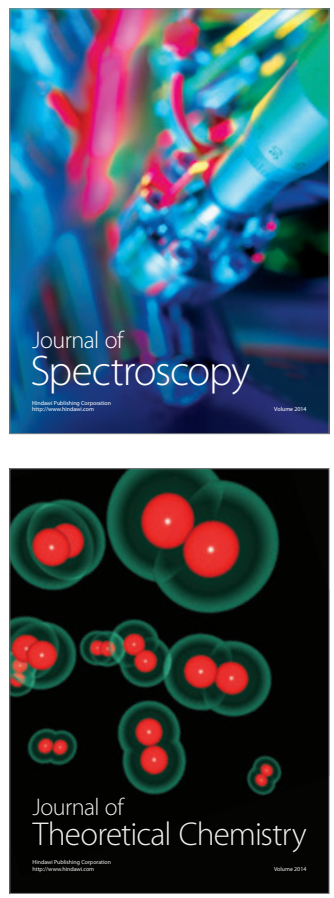
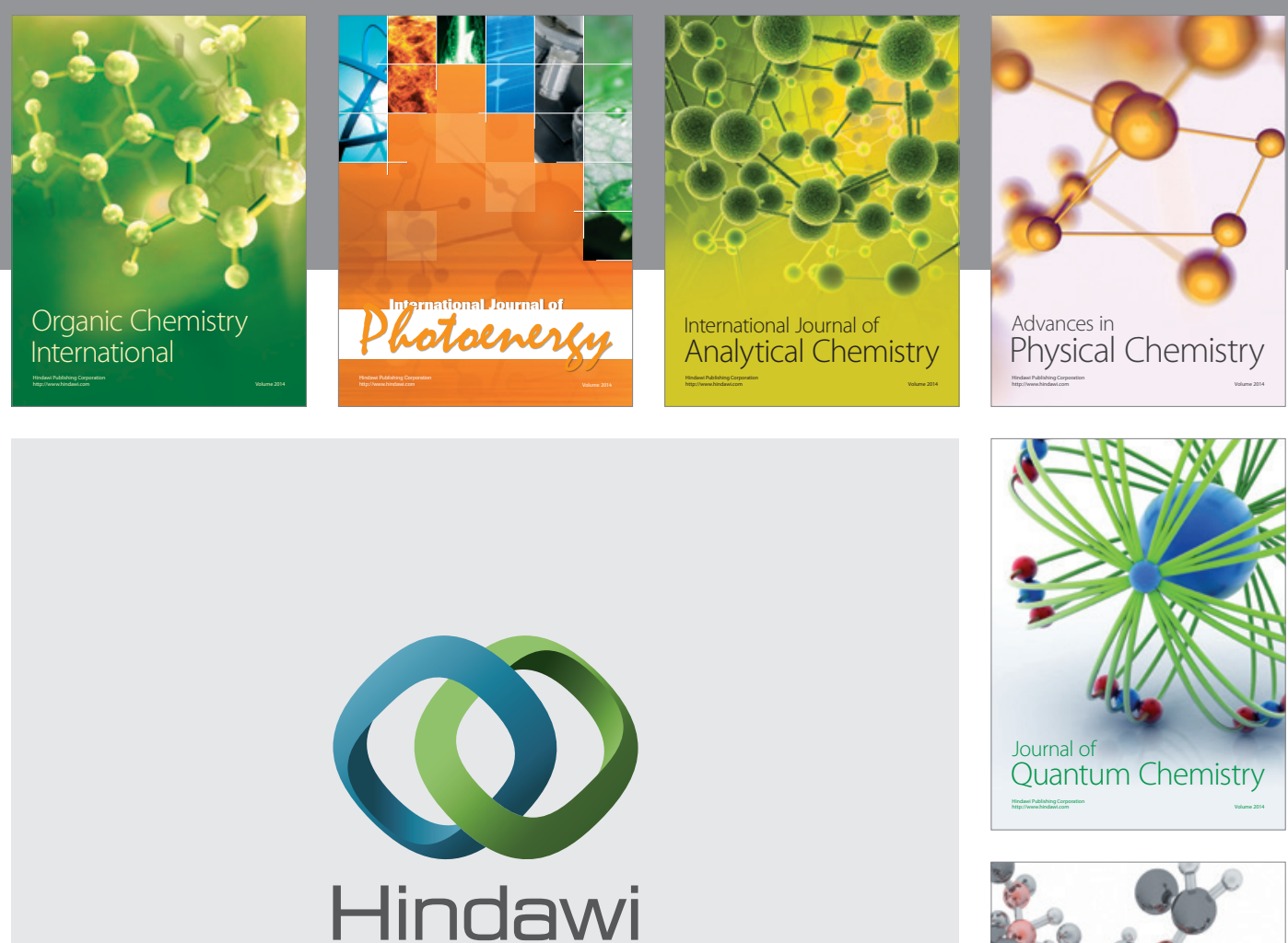

Submit your manuscripts at

http://www.hindawi.com

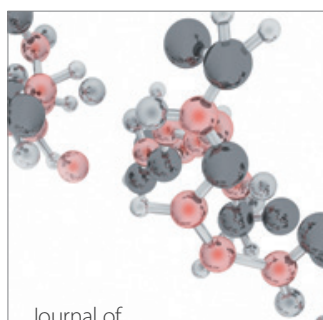

Analytical Methods

in Chemistry

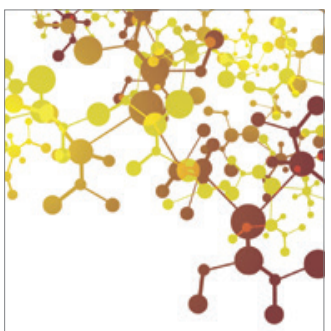

Journal of

Applied Chemistry

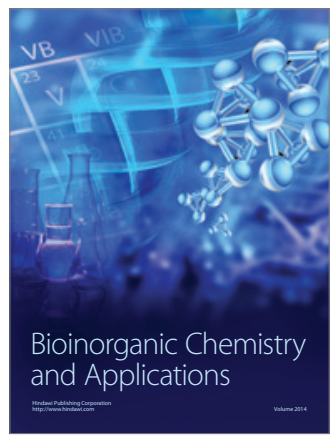

Inorganic Chemistry
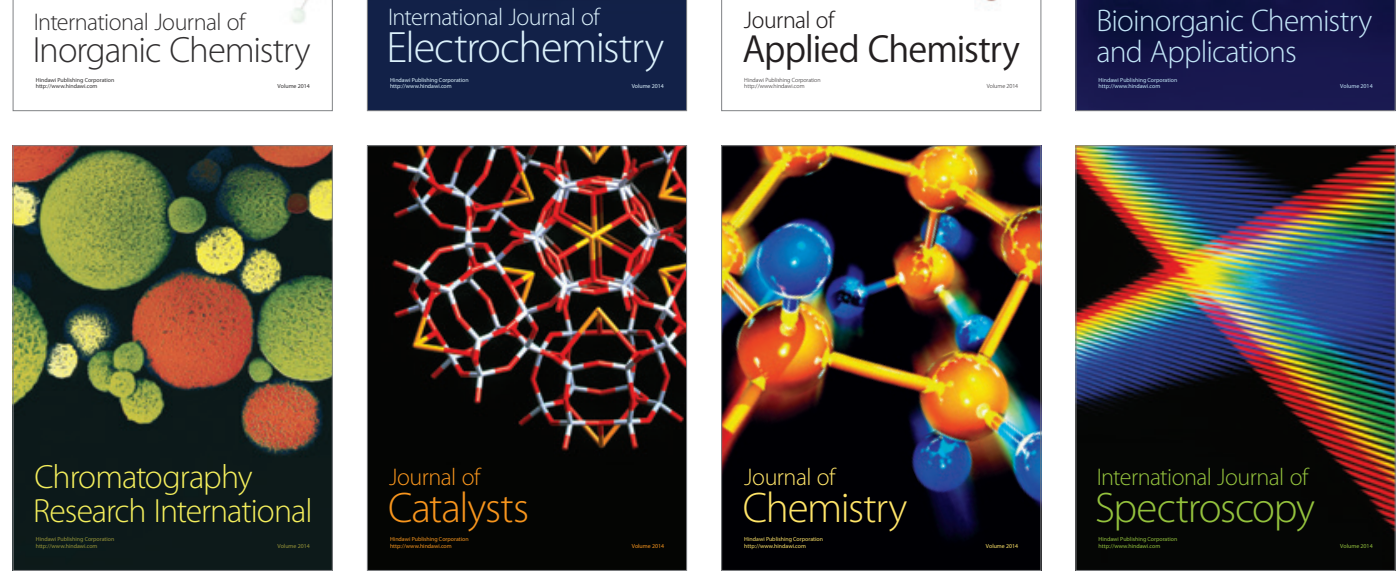